ВІСНИК

ОДЕСЬКОГО НАЦІОНАЛЬНОГО

МОРСЬКОГО УНІВЕРСИТЕТУ

№ 2 (65), 2021
HERALD

OF THE ODESSA NATIONAL

MARITIME UNIVERSITY № 2 (65), 2021

УДК 621.44:629.425

DOI 10.47049/2226-1893-2021-2-84-93

\title{
АНАЛИЗ ТЕРМОДИНАМИЧЕСКИХ ЦИКЛОВ \\ ГАЗОТУРБИННЫХ УСТАНОВОК С ИЗОБАРНЫМ И ИЗОХОРНЫМ ПРОЦЕССАМИ ПОДВОДА ТЕПЛОТЫ
}

\author{
А.А. Вассерман \\ доктор технических наук, профессор кафедры \\ «Судовые энергетические установки и техническая эксплуатация» \\ А.Г. Слынько \\ кандидат технических наук, профессор кафедры \\ «Судовые энергетические установки и техническая эксплуатация» \\ Одесский национальный морской университет
}

Аннотация. Рассматриваются термодинамические ичиль открытых газотурбинных установок с процессами подвода теплоты к рабочему телу по изобаре и изохоре. В результате теоретического анализа и сопоставительных расчётов установлено, что при различных условиях сравнения термический КПД цикла с изохорным подводом теплоты во многих случаях больше термического КПД иикла с изобарным подводом теплоты.

Ключевые слова: газотурбинная установка, изохорный и изобарный подвод теплоты, термический КПД, удельная мощчность.

УДК 621.44:629.425

DOI 10.47049/2226-1893-2021-2-84-93

\section{АНАЛІЗ ТЕРМОДИНАМІЧНИХ ЦИКЛІВ ГАЗОТУРБІННИХ УСТАНОВОК З ИЗОБАРНИМ ТА ИЗОХОРНИМ ПРОЦЕСАМИ ПІДВЕДЕННЯ ТЕПЛОТИ}

О.А. Вассерман

доктор технічних наук, професор кафедри «Суднові енергетичні установки та технічна експлуатація» О.Г. Слинько

кандидат технічних наук, професор кафедри «Суднові енергетичні установки та технічна експлуатація»

Одеський національний морський університет

Анотація. Розглядаються термодинамічні ичили відкритих газотурбінних установок з процесами підведення теплоти до робочого тіла по ізобарі та ізохорі. В результаті теоретичного аналізу і порівнювальних розрахунків встановлено, щзо при різних умовах порівняння термічний ККД ииклу з ізохорним підведенням теплоти в багатьох випадках більше термічного ККД ииклу з ізобарним підведенням теплоти.

Ключові слова: газотурбінна установка, ізохорне та ізобарне підведення теплоти, термічний ККД, питома потужність.

(C) Вассерман А.А., Слынько А.Г., 2021 
UDC 621.44:629.425

DOI 10.47049/2226-1893-2021-2-84-93

\title{
ANALYSIS OF GAS TURBINES PLANTS \\ THERMODYNAMIC CYCLES WITH HEAT SUPPLY PROCESSES AT CONSTANT PRESSURE AND VOLUME
}

\author{
A.A. Vasserman \\ Doctor of technical sciences, Professor of Department \\ A.G. Slyn ko \\ Candidate of technical sciences, Professor of Department \\ «Ships energetic plants and technical operation» \\ Odessa National Maritime University, Ukraine, Odessa
}

Abstract. Thermodynamic cycles of open gas turbines plants are considered with heat supply to working media processes at constant pressure and volume. As result of theoretical analysis and comparing calculations is established that at different conditions of comparison thermal coefficient of efficiency of cycle with heat supply at constant volume at many cases is greater than thermal of cycle with heat supply at constant pressure.

Keywords: gas turbine plant, heat supply at constant volume and pressure, thermal coefficient of efficiency, specific power.

Введение. Газотурбинные установки (ГТУ) - перспективный тип энергетических установок $[1 ; 2]$. Существенным преимуществом их перед паротурбинными установками является отсутствие котла, так как топливо сжигается в потоке рабочего тела. Газотурбинные установки получат всё большее распространение в стационарной энергетике и на транспортных судах по мере повышения их экономичности, экологичности и моторесурса.

В современных открытых ГТУ теплота к рабочему телу подводится в процессе сгорания топлива при постоянном давлении. Встречаются также открытые ГТУ со сгоранием топлива при постоянном объёме, в которых камера сгорания оборудуется управляемыми клапанами. Топливо в камере сгорает при постоянном объёме (при закрытых клапанах), а после конца сгорания открывается выпускной клапан и газы подаются на лопатки турбины. Если на моторесурс влияют конструктивные особенности таких ГТУ, то вопросы экономичности не очевидны.

Целью статьи является выполнение теоретического анализа и сопоставительных расчётов термодинамических циклов ГТУ с изобарным и изохорным подводом теплоты при различных условиях для определения соотношения их основных энергетических характеристик. 
Изложение основного материала. На рис. 1 на диаграмме $T, s$ изображены совместно циклы ГТУ с изобарным и изохорным подводом теплоты при одинаковых предельных температурах и степени повышения давления воздуха в компрессоре. При таком сопоставлении циклов видно, что в «изохорном» цикле 1-2-3'-4'-1 и «изобарном» 1-2-3-4-1 средние температуры подвода теплоты одинаковы, а средняя температура отвода теплоты ниже в «изохорном» цикле. Поэтому при указанных условиях термический КПД цикла с изохорным подводом теплоты выше.

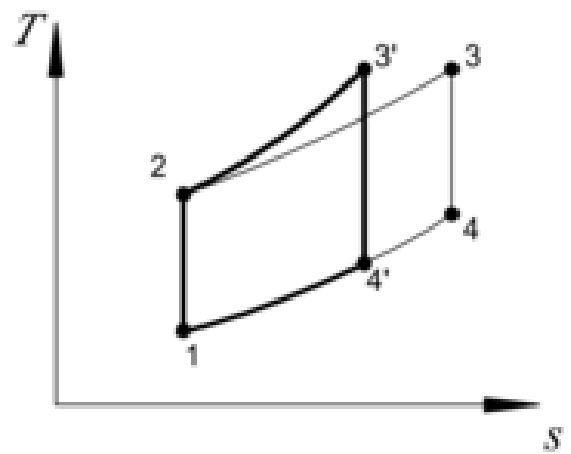

Рис. 1. Сопоставление термодинамических ииклов ГТУ с изобарным и изохорным подводом теплоты (1-2-3-4-1 и 1-2-3'-4'-1) при одинаковых $\beta$ и предельных температурах

Для количественной оценки соотношения термических КПД этих циклов выполнены расчёты при следующих исходных данных: температура и давление атмосферного воздуха $30{ }^{\circ} \mathrm{C}$ и 0,101325 МПа, степень повышения давления воздуха в компрессоре $\beta=7$, температура газов, поступающих на лопатки турбины $-850{ }^{\circ} \mathrm{C}$. Результаты расчётов приведены в табл. 1 , из которой видно, что при указанных выше условиях сравнения и исходных данных термический КПД цикла с изохорным подводом теплоты на 15,1% выше КПД цикла с изобарным подводом.

Анализируя табличные данные, можно сделать следующие выводы:

- при равных $\beta$ и предельных температурах цикл ГТУ с изохорным процессом подвода теплоты эффективнее: удельная мощность выше на 49,2 \%, а термический КПД - на 15,1 \%;

- отношение удельной мощности к подводимой теплоте в цикле с изохорным подводом теплоты в 2 раза выше, чем в цикле с изобарным подводом;

-отношение работы, потребляемой компрессором, к работе турбины в «изохорном» цикле уменьшается на $21 \%$, что соответственно уменьшает основной недостаток ГТУ - сопоставимые значения этих работ. 
ВІСНИК

ОДЕСЬКОГО НАЦІОНАЛЬНОГО МОРСЬКОГО УНІВЕРСИТЕТУ № 2 (65), 2021
HERALD

OF THE ODESSA NATIONAL

MARITIME UNIVERSITY № 2 (65), 2021

Таблицุа 1

Сопоставление характеристик ичиклов ГТУ с изобарным и изохорным процессами подвода теплоты при одинаковых предельных температурах и степени повышения давления $\beta$

\begin{tabular}{|l|c|c|c|}
\hline \multirow{2}{*}{ Характеристики циклов } & Размер & \multicolumn{3}{|c|}{ Подвод теплоты } \\
\cline { 3 - 5 } & -ность & по изобаре & по изохоре \\
\hline Температура воздуха после компрессора & ${ }^{\circ} \mathrm{C}$ & \multicolumn{2}{|c|}{255,4} \\
\hline Температура газов в начале расширения & ${ }^{\circ} \mathrm{C}$ & \multicolumn{2}{|c|}{850} \\
\hline Давление газов в начале расширения & МПа & 0,7093 & 1,5071 \\
\hline Давление газов в конце расширения & МПа & \multicolumn{2}{|c|}{0,101325} \\
\hline Температура газов в конце расширения & ${ }^{\circ} \mathrm{C}$ & 371,0 & 246,2 \\
\hline Средняя температура подвода теплоты & ${ }^{\circ} \mathrm{C}$ & \multicolumn{2}{|c|}{515,5} \\
\hline Средняя температура отвода теплоты & ${ }^{\circ} \mathrm{C}$ & 179,3 & 128,5 \\
\hline Количество подводимой теплоты & кДж/кг & 597,5 & 426,8 \\
\hline Количество отводимой теплоты & кДж/кг & 342,6 & 217,2 \\
\hline $\begin{array}{l}\text { Отношение работы компрессора } \\
\text { к работе турбины }\end{array}$ & $\%$ & 47,1 & 37,1 \\
\hline Удельная мощность ГТУ & кВт & 254,8 & 380,2 \\
\hline Повышение удельной мощности ГТУ & $\%$ & - & 49,2 \\
\hline $\begin{array}{l}\text { Отношение удельной мощности ГТУ } \\
\text { к подводимой теплоте }\end{array}$ & $\%$ & 42,7 & 89,1 \\
\hline Термический КПД & $\%$ & 42,65 & 49,09 \\
\hline Повышение термического КПД & $\%$ & - & 15,1 \\
\hline
\end{tabular}

Возможен вариант сравнения этих циклов при одинаковых начальных параметрах воздуха, равных $\beta$ и одинаковых количествах подводимой теплоты в циклах. Из диаграммы $T, s$ видно (рис. 2), что в этом случае при изохорном подводе теплоты средняя температура её подвода выше, чем при изобарном, а средняя температура отвода ниже, что соответственно сказывается на значениях термических КПД циклов.

Результаты расчёта характеристик циклов для этого варианта их сравнения приведены ниже в табл. 2. При расчётах приняты те же исходные данные для базового цикла, что и ранее. Из таблицы видно, что при принятых условиях сопоставления циклов термический КПД цикла с изохорным подводом теплоты на 19,1\% выше, чем у цикла с изобарным подводом. 


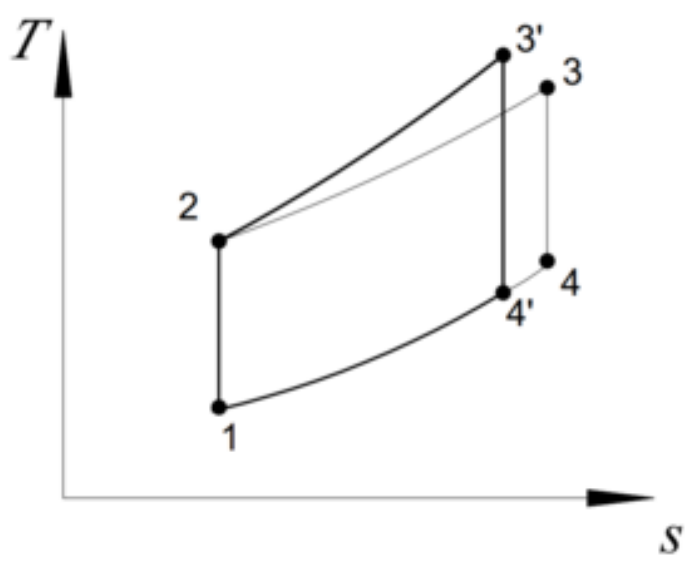

Рис. 2. Сопоставление термодинамических ииклов ГТУ с изобарным и изохорным подводом теплоты (1-2-3-4-1 и 1-2-3'-4'-1) при одинаковых начальных параметрах воздуха, равных $\beta$ и одинаковых количествах подводимой теплоты

Анализируя данные табл. 2, можно заключить следующее:

- при одинаковых параметрах воздуха, всасываемого компрессором, степени повышения давлении $\beta$ и количествах теплоты, подводимой в сопоставляемых термодинамических циклах, удельная мощность турбины в цикле с изохорным подводом теплоты больше на 112,8 \%, а термический КПД - на 19,1 \% по сравнению с циклом с изобарным подводом теплоты;

- отношение удельной мощности турбины к подводимой теплоте в «изохорном» цикле выше в 2,1 раза при указанных условиях сопоставления;

- отношение работы, потребляемой компрессором, к работе турбины уменьшается в 1,6 раза, что способствует повышению эффективности цикла ГТУ с изохорным процессом подвода теплоты.

На рис. 3 изображены совместно на диаграмме T,s циклы ГТУ с изобарным и изохорным подводом теплоты при одинаковых процессах сжатия воздуха в компрессоре и одинаковых температурах газов в конце расширения в турбине. При сравнении таких циклов видно, что в изохорном цикле 1-2-3'-4-1 средняя температура подвода теплоты в процессе 2-3' выше, а средняя температура отвода теплоты в процессе 4-1 такая же, как в изобарном. Поэтому при указанных условиях, как и в предыдущем варианте сопоставления, термический КПД цикла с изохорным подводом теплоты выше. 
ВІСНИК

ОДЕСЬКОГО НАЦІОНАЛЬНОГО

МОРСЬКОГО УНІВЕРСИТЕТУ

№ 2 (65), 2021
HERALD

OF THE ODESSA NATIONAL

MARITIME UNIVERSITY № 2 (65), 2021

Таблииа 2

Сравнение характеристик ичклов ГТУ с изобарным

и изохорным подводом теплоты при одинаковых начальных параметрах воздуха, равных $\beta$ и одинаковых количествах подводимой теплоты

\begin{tabular}{|l|c|c|c|}
\hline \multirow{2}{*}{ Характеристики циклов } & \multirow{2}{*}{$\begin{array}{l}\text { Раз- } \\
\text { мер- }\end{array}$} & \multicolumn{3}{|c|}{ Подвод теплоты } \\
\cline { 3 - 5 } & ность & по изобаре & по изохоре \\
\hline Температура воздуха после компрессора & ${ }^{\circ} \mathrm{C}$ & \multicolumn{3}{|c|}{255,4} \\
\hline $\begin{array}{l}\text { Температура газов в начале расшире- } \\
\text { ния }\end{array}$ & ${ }^{\circ} \mathrm{C}$ & 850 & 1087,8 \\
\hline Давление газов в начале расширения & МПа & 0,7093 & 1,0878 \\
\hline Давление газов в в конце расширения & МПа & \multicolumn{2}{|c|}{0,101325} \\
\hline Температура газов в конце расширения & ${ }^{\circ} \mathrm{C}$ & 371,0 & 322,6 \\
\hline Средняя температура подвода теплоты & ${ }^{\circ} \mathrm{C}$ & 515,8 & 607,0 \\
\hline Средняя температура отвода теплоты & ${ }^{\circ} \mathrm{C}$ & 179,3 & 160,0 \\
\hline Количество подводимой теплоты & кДж/кг & \multicolumn{2}{|c|}{597,5} \\
\hline Количество отводимой теплоты & кДж/кг & 342,6 & 294,0 \\
\hline $\begin{array}{l}\text { Отношение работы компрессора } \\
\text { к работе турбины }\end{array}$ & $\%$ & 47,1 & 29,5 \\
\hline Удельная мощность ГТУ & КВт & 254,8 & 542,1 \\
\hline Повышение удельной мощности ГТУ & $\%$ & - & 112,8 \\
\hline $\begin{array}{l}\text { Отношение удельной мощности ГТУ } \\
\text { к подводимой теплоте }\end{array}$ & $\%$ & 42,7 & 90,8 \\
\hline Термический КПД & $\%$ & 42,65 & 50,79 \\
\hline Повышение термического КПД & $\%$ & - & 19,1 \\
\hline
\end{tabular}

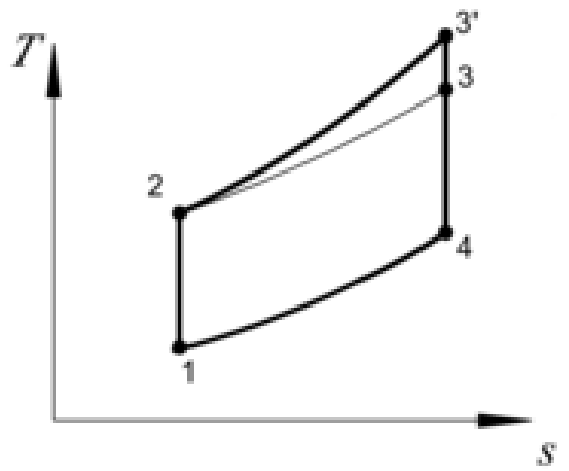

Рис. 3. Сопоставление термодинамических ииклов ГТУ с изобарным и изохорным прочессами подвода теплоты (1-2-3-4-1 и 1-2-3'-4-1) при одинаковых $\beta$ и параметрах газов в конце расширения 
Для определения значений термического КПД рассматриваемых циклов выполнены расчёты при тех же исходных данных и при условии, что в обоих сопоставляемых циклах одинаковы $\beta$ и параметры газа в конце расширения. Результаты расчётов приведены ниже в табл. 3.

Таблицуа 3

Сопоставление характеристик цииклов ГТУ с изобарным и изохорным подводом теплоты при одинаковых начальных параметрах воздуха, равных $\beta$ и одинаковых параметрах газа в конце расширения

\begin{tabular}{|c|c|c|c|}
\hline \multirow{2}{*}{ Характеристики циклов } & \multirow{2}{*}{$\begin{array}{l}\text { Раз- } \\
\text { мер- } \\
\text { ность }\end{array}$} & \multicolumn{2}{|c|}{ Подвод теплоты } \\
\hline & & по изобаре & по изохоре \\
\hline Температура воздуха после компрессора & ${ }^{\circ} \mathrm{C}$ & \multicolumn{2}{|c|}{255,4} \\
\hline Температура газов в начале расширения & ${ }^{\circ} \mathrm{C}$ & 850 & 1245,2 \\
\hline Давление газов в начале расширения & МПа & 0,7093 & 2,03736 \\
\hline Давление газов в в конце расширения & МПа & \multicolumn{2}{|c|}{0,101325} \\
\hline Температура газов в конце расширения & ${ }^{\circ} \mathrm{C}$ & \multicolumn{2}{|c|}{371,0} \\
\hline Средняя температура подвода теплоты & ${ }^{\circ} \mathrm{C}$ & 515,8 & 664,9 \\
\hline Средняя температура отвода теплоты & ${ }^{\circ} \mathrm{C}$ & \multicolumn{2}{|c|}{179,3} \\
\hline Количество подводимой теплоты & кДж/кг & 597,5 & 710,4 \\
\hline Количество отводимой теплоты & кДж/кГ & \multicolumn{2}{|c|}{342,6} \\
\hline $\begin{array}{l}\text { Отношение работы компрессора } \\
\text { к работе турбины }\end{array}$ & $\%$ & 47,1 & 25,8 \\
\hline Удельная мощность ГТУ & KBT & 254,8 & 651,9 \\
\hline Повышение удельной мощности ГТУ & $\%$ & - & 155,8 \\
\hline $\begin{array}{l}\text { Отношение удельной мощности ГТУ } \\
\text { к подводимой теплоте }\end{array}$ & $\%$ & 42,7 & 91,8 \\
\hline Термический КПД & $\%$ & 42,65 & 51,77 \\
\hline Повышение термического КПД & $\%$ & - & 21,4 \\
\hline
\end{tabular}

Из анализа табличных данных можно сделать следующие выводы:

- при равных $\beta$ и параметрах газа на выходе из турбины цикл ГТУ с изохорным процессом подвода теплоты более эффективный - удельная мощность выше в 2,5 раза, а термический КПД - на 21,4%;

- отношение удельной мощности турбины к подводимой теплоте выше в 2,1 раза при указанных условиях сопоставления;

- отношение работы потребляемой компрессором, к работе турбины уменьшается в 1,8 раза, что соответственно уменьшает основной 
недостаток ГТУ, что является главной задачей по усовершенствованию циклов ГТУ.

- при изохорном подводе теплоты температура газов, поступающих в турбину, существенно выше, чем при изобарном подводе, что неблагоприятно скажется на моторесурсе ГТУ.

Теперь сравним рассматриваемые циклы при одинаковых начальных параметрах воздуха, всасываемого компрессором, и газа, поступающего в турбину. Из диаграммы $T, s$ видно (рис. 4), что в этом случае при одинаковой средней температуре отвода теплоты средняя температура её изохорного подвода ниже, чем изобарного, что соответственно сказывается на значениях термического КПД.

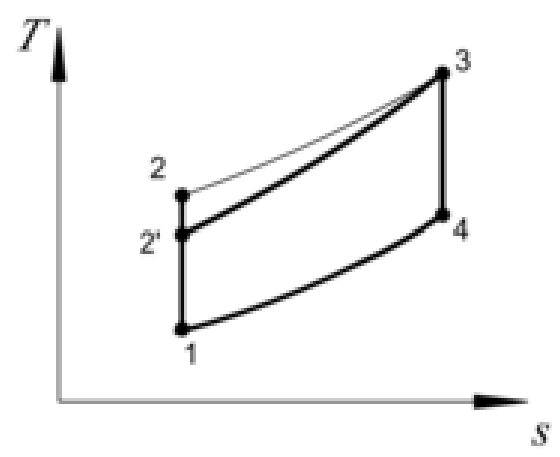

Рис. 4. Сопоставление термодинамических циклов ГТУ

с изобарным и изохорным подводом теплоты (1-2-3-4-1 и 1-2'-3-4-1) при одинаковых предельных состояниях рабочего тела

Результаты сопоставительных расчётов для этого варианта приведены в табл. 4. При расчётах приняты те же исходные данные и условие равенства параметров рабочего тела в предельных состояниях циклов. Из таблицы видно, что при таких условиях термический КПД «изохорного» цикла на 18,4 \% ниже, чем цикла с изобарным подводом теплоты, а значение $\beta$ изохорного цикла существенно уменьшилось.

Из анализа данных табл. 4 можно сделать следующие выводы:

- значение $\beta$ в цикле с изохорным процессом подвода теплоты резко уменьшилось, поэтому уменьшились средняя температура подвода теплоты и термический КПД (на 18,4 \%);

- при равных параметрах рабочего тела в предельных состояниях сопоставляемых циклов удельная мощность турбины в цикле с изохорным подводом теплоты больше на $54,2 \%$, а её отношение к подводимой теплоте больше в 1,75 раза по сравнению с циклом с изобарным подводом теплоты; 
Сопоставление характеристик ииклов ГТУ с изобарным и изохорным процессами подвода теплоты при одинаковых предельных состояниях рабочего тела

\begin{tabular}{|l|c|c|c|}
\hline \multirow{2}{*}{\multicolumn{1}{|c|}{ Характеристики циклов }} & $\begin{array}{c}\text { Раз- } \\
\text { мер- }\end{array}$ & \multicolumn{2}{|c|}{ Подвод теплоты } \\
\cline { 3 - 5 } & ность & по изобаре & по изохоре \\
\hline Степень повышения давления воздуха & & 7,0 & 2,437 \\
\hline Температура воздуха после компрессора & ${ }^{\circ} \mathrm{C}$ & 255,4 & 117,9 \\
\hline Температура газов в начале расширения & ${ }^{\circ} \mathrm{C}$ & \multicolumn{2}{|c|}{850} \\
\hline Давление газов в начале расширения & МПа & \multicolumn{2}{|c|}{0,7093} \\
\hline Давление газов в в конце расширения & МПа & \multicolumn{2}{|c|}{0,101325} \\
\hline Температура газов в конце расширения & ${ }^{\circ} \mathrm{C}$ & \multicolumn{2}{|c|}{371,0} \\
\hline Средняя температура подвода теплоты & ${ }^{\circ} \mathrm{C}$ & 515,8 & 420,8 \\
\hline Средняя температура отвода теплоты & ${ }^{\circ} \mathrm{C}$ & \multicolumn{2}{|c|}{179,3} \\
\hline Количество подводимой теплоты & кДж/кг & 597,5 & 525,5 \\
\hline Количество отводимой теплоты & кДж/кг & \multicolumn{2}{|c|}{342,6} \\
\hline $\begin{array}{l}\text { Отношение работы компрессора } \\
\text { к работе турбины }\end{array}$ & $\%$ & 47,1 & 18,3 \\
\hline Удельная мощность ГТУ & кВт & 254,8 & 393,0 \\
\hline Повышение удельной мощности ГТУ & $\%$ & - & 54,2 \\
\hline $\begin{array}{l}\text { Отношение удельной мощности ГТУ } \\
\text { к подводимой теплоте }\end{array}$ & $\%$ & 42,7 & 74,8 \\
\hline Термический КПД & $\%$ & 42,65 & 34,80 \\
\hline Понижение термического КПД & $\%$ & - & $-18,4$ \\
\hline
\end{tabular}

- отношение работы, потребляемой компрессором, к работе турбины в «изохорном» цикле меньше в 2,6 раза, что соответственно уменьшает основной недостаток ГТУ - сопоставимость этих работ.

Выводы. Теоретический анализ и расчёты показали, что термический КПД цикла ГТУ с изохорным подводом теплоты выше КПД цикла с её изобарным подводом как при одинаковых предельных температурах циклов, так и при одинаковых количествах подводимой теплоты, а также при одинаковых процессах сжатия воздуха и одинаковых температурах газов в конце расширения. Отношение работы, потребляемой компрессором, к работе турбины в ГТУ с изохорным подводом теплоты 
меньше, чем в ГТУ с изобарным подводом, что является положительным фактором.

ГТУ с изохорным подводом теплоты конструктивно сложнее по сравнению с ГТУ с изобарным подводом. Тем не менее, для использования в стационарных условиях при большой мощности с экономической и экологической точек зрения они предпочтительнее.

\section{СПИСОК ЛИТЕРАТУРЫ}

1. Артемов, Г.А., Горбов, В.М., Романовский, Г.Ф. Судовые установки с газотурбинными двигателями. Николаев: УГМТУ, 1997. $233 \mathrm{c}$.

2. Вассерман, О.А., Слинько, О.Г., Шутенко, М.А. Інноваційні термодинамічні ичили енергетичних установок. Одесса: Фенікс, 2020. 184 c.

\section{REFERENCES}

1. Artemov, G.A., Gorbov, V.M. and Romanovskiy, G.F. Sudovye ustanovki $s$ gazoturbinnymi dvigatelyami. Nikolaev: UGMTU. 1997. 233 p. (Ship `s plants with gas turbines engines). Nikolaev: USMTU. -233 .

2. Vasserman, A.A., Slyn ko, A.G. and Shutenko, M.A. Innovatsiyni termodinamichni tsikly energeticheskikh ustanovok. - Odessa: Feniks. 2020. 184 p. (Innovatory thermodynamic cycles of energetic plants). - Odessa: Feniks. - 184 p.

Стаття надійшла до редакиії 08.02.2021

Посилання на статтю: Вассерман А.А., Слынько А.Г. Анализ термодинамических циклов газотурбинных установок с изобарным и изохорным процессами подвода теплоты // Вісник Одеського національного морського університету: Зб. наук. праць, 2021. № 2(65). C. 84-93. DOI 10.47049/ 2226-1893-20212-84-93.

Article received 08.02.2021

Reference a JournalArtic: Vasserman A.A., Slyn`ko A.G. Analysis of gas turbines plants Thermodynamic cycles with heat supply processes at constant pressure and volume // Herald of the Odessa national maritime university. 2021. 2(65). 84-93. DOI 10.47049/ 2226-1893-2021-2-84-93. 